\title{
Editorial
}

\section{Estableciendo prioridades de la investigacion en salud Setting priorities in health research}

\author{
Fortich-Mesa Natalia $^{1}$
}

En los últimos años en Colombia se ha observado un aumento en la producción científica derivada de los grupos de Investigación pertenecientes a las Ciencias Médicas y de la Salud. De acuerdo con los últimos reportes emitidos por Colciencias en el año 2014, 685 grupos de esta área del conocimiento fueron reconocidos, de estos 44 en categoría A1, 56 en categoría A y 178 en categoría B (1). Así mismo se ha realizado un esfuerzo considerable por incrementar en Colombia los recursos públicos destinados a promover la ciencia, la tecnología y la innovación. La Ley 643 de 2001 establece la destinación de las rentas del monopolio al sector salud, el 7\% con destino al Fondo de Investigación en salud y destinados a proyectos de investigación en salud de los departamentos y el Distrito Capital por un valor de los 30 mil millones de pesos. En el año 2014 de los seis principales rubros públicos destinados a CT\&I, el presupuesto de Inpulsa, presupuesto de Colciencias, recursos del SENA para desarrollo tecnológico y competitividad, los beneficios tributarios para inversiones en ciencia, tecnología e innovación, fondo de Ciencia, Tecnología e Innovación del Sistema General de Regalías, y presupuesto de Corpoica y otras inversiones en CT\&I para el sector agropecuario (2). Estos recursos han permitido un aumento considerable en el número de proyectos en Salud financiados por año. El Programa Salud de Colciencias ha financiado más de 1.000 proyectos de investigación, principalmente en la modalidad de recuperación contingente y con ello ha aportado de manera importante al crecimiento de las capacidades nacionales de investigación en salud. El Programa también ha apoyado la consolidación de grupos, centros y entidades que investigan en salud, y ha promovido sus alianzas nacionales e internacionales Sin embargo, las problemáticas y desigualdades en salud y los recursos destinados a la investigación siguen siendo un problema actual.

${ }_{1}^{1}$ Odontóloga, Endodoncista. Magister en Epidemiologia Clínica. Editora revista Ciencia y Salud Virtual. Facultad de Ciencias de la Salud, Corporación Universitaria Rafael Núñez, Cartagena - Colombia 
Investigar en salud significa generar conocimiento para comprender mejor los problemas que afectan la salud de la población y a partir de ello proponer estrategias y soluciones (3). En ese sentido, la investigación es una función que todo sistema de salud requiere cumplir puesto que ello contribuye con la prevención y control de los problemas sanitarios. En investigación, como en tantas otras actividades en las que no hay suficientes recursos para acometer todos los objetivos posibles, es necesario establecer prioridades. Además de la priorización de la investigación también debe realizarse una priorización interna que ordene la propia agenda de investigación en servicios de salud. En países como España quienes han utilizados diversas metodologías que intentan priorizar las temáticas en investigación en salud, Bernal- Delgado, et al, con 13 expertos realizaron una encuesta estructurada con una técnica grupal mixta, desarrollada en 2 fases consecutivas: grupo nominal y método Delphi. Se identificaron prioridades de investigación en servicios de salud que fueron puntuadas de la siguiente manera: de 7 a 9 , muy relevante; de 4 a 6 , relevancia intermedia, y de 1 a 3 , poco o nada relevante. En los resultados identificaron 53 temas de investigación. Se clasificaron como prioritarios los temas relacionados con estrategias para mejorar la efectividad de la atención sanitaria, la información a los pacientes, la calidad y la seguridad de la atención, la equidad y la accesibilidad de los servicios, y la sostenibilidad del sistema sanitario (4).

Una prioridad es un hecho o condición que se considera más importante que otro y está basada en la valoración que le establecen las personas, grupos y las instituciones involucradas. Así, para el caso de la investigación en salud, los investigadores, los profesionales de la salud que brindan atención, los decisores del gobierno, las organizaciones del sector público y el privado, las potenciales entidades financiadoras y la comunidad, podrían tener diferentes puntos de vista al momento de establecer prioridades. Establecer prioridades implica tomar decisiones y planificar el buen uso de los limitados recursos. Luego de ello, el siguiente paso será identificar las agendas de investigación mediante un proceso estratégico para asegurar que las organizaciones sean transparentes y responsables en el gasto de los fondos, que las partes interesadas participen en la toma de decisiones y que las investigaciones sean útiles. La utilidad y el impacto de las investigaciones basadas en prioridades podrán brindar beneficios a la sociedad

(5).

Actualmente está planeación se sintoniza con los lineamientos de la Política Nacional de Fomento a la Investigación y la Innovación "Colombia Construye y Siembra Futuro", y apunta a que la investigación en salud en Colombia produzca conocimiento que aporte al mejoramiento de la salud, de las condiciones de vida, de la equidad, del desarrollo social y por tanto económico de las regiones y poblaciones (Colciencias 2014).

Se espera que al establecer Prioridades de investigación en salud para nuestro país se permita la optimización de recursos para realizar investigación e impactar 
positivamente en la calidad de la misma,logrando de esta manera mejorar la eficiencia y coordinar los esfuerzos de todos los actores del sistema de salud.

\section{BIBLIOGRAFIA}

1. Informe de Convocatoria Nacional para el Reconocimiento y Medición de Grupos de Investigación, Desarrollo Tecnológico o de Innovación y para el Reconocimiento de Investigadores del Sistema Nacional de Ciencia, Tecnología e Innovación, 2014.

2. Gómez, H J, Mitchell D. Innovación y emprendimiento en Colombia: Balance, perspectivas y recomendaciones de política, 2014-2018. Cuadernos Fedesarrollo. 2014.

3. White et al. Investigación sobre Servicios de Salud: una antología. Washington. D. C: OPS; 1992

4. Bernal-Delgado Enrique, Peiró Salvador, Sotoca Rafael. Prioridades de investigación en servicios sanitarios en el Sistema Nacional de Salud: Una aproximación por consenso de expertos. Gac Sanit. 2006; 20(4): 287-294.

5. V. Ortún-Rubio, J.L. Pinto-Prades y J. Puig-Junoy. El establecimiento de prioridades. Atención Primaria. Vol. 27. Núm. 9 mayo 2001, 